eliminated, and the pool gazer has a clear view of what lies beneath the surface. One must not forget to direct attention to the great developments that have been made within the last year in the applications of 'Perspex', the synthetic product having the appearance and most of the properties of glass, without its defects, to which reference was made last year. A new method has been devised of making optical lenses from this material (see Nature, February 20, p. 336), and it will be a matter of much interest to watch how far it can be used in optical instruments of precision.

On the whole, one's impression is that those indus. tries which may be regarded as more or less specifically scientific are in step with the general advance of industry and, in particular, alive to the opportunities created for new and, in some cases, striking developments.

\title{
Figures of the Earth and Moon
}

\begin{abstract}
A RECENT paper by Dr. Harold Jeffreys (Mon. Not. Roy. Astro. Soc., 97, $1 ; 1936$ ) deals with some well-known articles by de Sitter (Bull. Astr. Soc. Neth., 2, 55 ; 4, 129 . Also K. Akad. Wetens. Amst., 17). De sitter assumed hydrostatic stress in the earth's interior, and computed the ellipticity and related constants from the precessional constant. On comparing the results with the motion of the moon's node and perigee, the greater part of which can be explained by Brown's theory, there is a balance depending upon the figures of the earth and moon. The former was taken by de Sitter to be calculable from his theory, and the small balance he attributed to the moon's ellipticities. As Jeffreys points out, however, the assumption of hydrostatic stress in the interior does not agree with other data. For example, accepting his solution, the probable error of the difference between gravity at the poles and at the equator is 1 milligal $\left(0.001 \mathrm{~cm} . / \mathrm{sec}^{2}\right)^{2}$, but Heiskanen's ellipticity of the equator alone gives a variation of 38 milligals at the extremes. In addition, the relativity correction was applied by de Sitter with the wrong sign, a fact which he pointed out to Jeffreys about five years ago, and this produced errors in some of the constants.

Jeffreys deals with the problem in a very thorough manner, certain geophysical information being now svailable which was unknown to de Sitter, and arrives at some interesting results. Although de Sitter made
\end{abstract}

use of erroneous data which rendered his theory of the figure of the earth a little unsatisfactory, nevertheless the main ellipticity effects do not show much departure from his theory. The ellipticity of the earth is found to be $1 / 296 \cdot 38 \pm 0 \cdot 51$, and the corresponding gravity formula is

$$
g=978 \cdot 051\left\{1+\underset{(0 \cdot 005282 \pm 0 \cdot 000006) \sin ^{2} \varphi-}{\left.0 \cdot 000007 \sin ^{2} 2 \varphi\right\} .}\right.
$$

He thinks that the accuracy of the formula is genuine so far as the term in $\sin ^{2} \varphi$ is concerned. Other formulæ may suffer from greater inaccuracies because the methods of analysis may fail to allow for other terms.

Dealing with the moon, Jeffreys finds that the ellipticity of the equator is only about one-sixth that of the disk, and from this he concludes that when the moon solidified it was in a state of free rotation, the period being 3.5 days. In "The Earth" (second ed., pp. 228-9) he finds that the moon last adjusted itself to the hydrostatic state when its distance from the earth was about 87,000 miles, and its period of revolution and rotation $6 \cdot 3$ days. How. ever, as he points out, the solution providing $3 \cdot 5$ days is only an ad hoc hypothesis. La Place's suggestion that the excess ellipticity may be due to random changes during solidification is probably as near the truth as Jeffreys's hypothesis. Obviously further research will modify some of the results which have been attained.

\section{Hydrides of Boron}

\footnotetext{
$\mathrm{IN}^{\mathrm{N}}$ the December issue of the Berichte der deutschen 1 chemischen Gesellschaft, Dr. E. Wiberg reviews at considerable length the experimental evidence from which the structure of the puzzling hydrides of boron may be deduced. That considerable difficulty has been encountered during the last decade in formu. lating the electronic structure of these compounds will be apparent from the fact that such unsatisfactory devices as singlet linkages, polyvalent hydrogen, a co-ordination number of five for boron, electronic septets, even the sharing of $K$-electrons, a new but unexplained kind of 'electrostatic-electromagnetic' valency and inequality of the two boron atoms, have all been requisitioned at various times in order to find plausible explanations of the existence of the simple compound known, perhaps wrongly, as boroethane, $\mathrm{B}_{2} \mathrm{H}_{6}$.
}

Recent work has thrown new light upon this problem, which has been greatly simplified. The author brings forward both chemical and physical evidence to show that, instead of ethane, one should rather regard ethylene as the carbon analogue of diborane (boroethane), since it possesses an unsaturated character; but the analogy should not be pushed too far, since the boron hydrides are also acids. Their acidic character has been rather concealed by the fact that their salts are very easily decomposed by water, but they combine with ammonia to form true salts. Thus diborane combines with two and tetraborane with four molecules of ammonia to form salts, which are electrolytes when dissolved in liquid ammonia although water decomposes them. That they are indeed ammonium salts rather than ammines is shown by the fact that an 
ammoniacal solution of borontrimethylmonoammine is non-conducting. Thus diborane is a dibasic, tetraborane a tetrabasic acid, and they may be formulated thus: $\mathrm{H}_{2}\left[\mathrm{~B}_{2} \mathrm{H}_{4}\right]$ and $\mathrm{H}_{4}\left[\mathrm{~B}_{4} \mathrm{H}_{6}\right]$.

The unsaturated character of these hydrides has been proved by both spectroscopic and chemical evidence. Thus diborane and ethylene give similar absorption bands, where ethane shows none at all, in the region between 210 and $186 \mu \mu$. Moreover, when shaken with alkali amalgam, the boranes react additively with the alkali metals thus:

$$
\mathrm{B}_{2} \mathrm{H}_{6}+2 \mathrm{~K}=2 \mathrm{~K}+\left[\mathrm{B}_{2} \mathrm{H}_{6}\right]^{--} \text {. }
$$

A molecular weight determination deduced from measurement of its diamagnetic susceptibility shows that the borane molecule has not been ruptured into simpler molecules in this reaction. The resulting potassium salt can be sublimed unchanged at about $400^{\circ} \mathrm{C}$., so that the bivalent negative ion $\mathrm{B}_{2} \mathrm{H}_{6}--$ with an ethane-like structure is much more stable than the unsaturated 'ethylenic' molecule $\mathrm{B}_{2} \mathrm{H}_{6}$, for which the formula $2 \mathrm{H}+\left[\mathrm{BH}_{2}: \mathrm{BH}_{2}\right]^{-}-$must now be adopted.

The unsaturated character of diborane accounts also for its reactions with water and with hydrogen chloride, since in both cases the additive products which are first formed split off hydrogen to produce a new unsaturated product; this then reacts further in the same way until we arrive at boric acid or boron polyhalides as final products. Some of the intermediate compounds have even been isolated. Similarly, the formula of tetraborane is written thus :

$$
4 \mathrm{H}+\left[\mathrm{BH}_{2}: \mathrm{BH} \cdot \mathrm{BH}: \mathrm{BH}_{2}\right)^{---}
$$

Two different groups of hydrides have been recognized, corresponding with the general formulæ $\mathrm{B}_{n} \mathrm{H}_{n+4}$ and $\mathrm{B}_{n} \mathrm{H}_{n+6}$. At present, only the first mombers of each group have been investigated experimentally, but in both cases the chemical evidence has been supported by that based on measurements of parachor, dipole moments, magnetic properties and ultra-violet absorption spectra.

\section{Plankton Research and Sea Fisheries}

A RECENT publication by R. E. Savage and R. S. Wimpenny ("Phytoplankton and the Herring", Part 2 (1933 and 1934), Min. Agric. Fish., Fishery Invest., Ser. II, 15, No. I (1936), pp. 1-88. London: H.M. Stationery Office, 1936. $4 s .6 d$. gives detailed information on the plankton conditions in the southern North Sea and their relations with the herring fishery in the years 1933 and 1934. This is a continuation of work already begun in 1921 and follows on a previous report for the years 1921--32.

The year 1933 was remarkable for unusually dense patches of the diatoms Rhizosolenia styliformis and Biddulphia sinensis. The former is associated with the current system in the neighbourhood of the south-west Dogger Bank Swirl; and the unusual degree of production in 1933 appeared to owe its origin to a strong incursion of oceanic bottom water, from the north, rich in nutrient salts. The arrival of the East Anglian herring shoals was delayed by these diatom patches in October 1933. A remarkable condition is recorded in May 1933, when a large area was covered with masses of the diatom Coscinodiscus concinnus to a depth of four feet, in which several guillemots and puffins were found floating dead. This was apparently being eaten by fulmar petrels.
Increasing attention to detail in this long-continued plankton programme is producing indications of new lines for research. The relation between the distribution and drift of the plankton with the water circulation is gradually being disclosed, as well as certain interrelationships between the phytoplankton and the zooplankton which call for further observation. Notable among these is evidence that higher proportions of the eggs and young stages of plankton animals are to be found within the diatom patches than in the surrounding areas. Adult plankton animals and herrings also appear to be massed against the edges of the phytoplankton patches. Evidence is fortheoming that the distribution of the young stages of the animals may be associated with the high oxygen content of the diatom patches.

The authors intend to investigate this problem further, but whatever be the true significance, it is clear that this continued routine research is developing on expanding lines which will lead to a better understanding of the biology of the plankton in the future. The work is carried on throughout in close collaboration with the hydrographers.

\section{University Events}

LONDON.- The title of professor of biochemistry in the University has been conferred on Dr. A. C. Chibnall in respect of the post held by him at the Imperial College-Royal College of Science.

The title of emeritus professor of mining geology in the University has been conferred on Prof. C. G. Cullis, on his retirement from the University professorship of mining geology at the Imperial College -Royal College of Science.

Dr. F. G. Gregory has been appointed as from October 1 to the University chair of plant physiology tenable at the Imperial College-Royal College of Science. Since 1931, he has been assistant director of the Research Institute of Plant Physiology at the Imperial College.

The following have been appointed fellows of King's College : Prof. F. A. P. Aveling, professor of psycho. logy since 1931; Miss Agnes S. Paul, lecturer in classies since 1932; Col. G. S. Szlumper, assistant general manager of the Southern Railway, and a vice-president of the Engineering Branch of the Old Students' Association; Mr. S. J. Worsley, academic registrar and acting principal of the University.

Prof. Raymond Pearl, professor of biology in the School of Hygiene and Public Health of Johns Hopkins University, has been appointed Heath Clark lecturer for the year 1937.

The degree of D.Sc. in mathematics has been conferred on A. C. Offord, of University College, and that of D.Sc in physiology on Miss M. M. A. Murray, a recognized teacher at Bedford College.

Oxford.-Prof. A. G. Tansley, Sherardian professor of botany and fellow of Magdalen College since 1927 , is retiring under the age-limit as from July 31 , 1937. Applications for the vacant professorship should reach the Registrar by April 17. The Board of the Faculty of Biological Sciences has recommended that the new professor should be primarily an ecologist.

The Nuffield professors, Prof. H. W. B. Cairns, Balliol, and Prof. R. R. Macintosh, Pembroke, and also Dr. S. Zuckerman, Christ Church, have received the degree of M.A. by decree. 